Proceedings

\title{
Analysis of the Successional Patterns of Insects on the Remains of Methadone-Dependent Rabbits ${ }^{\dagger}$
}

\author{
Davood Keshavarzi
}

Citation: Keshavarzi, D. Analysis of the Successional Patterns of Insects on the Remains of Methadone-Dependent Rabbits, in Proceedings of the 1st International Electronic Conference on Entomology, 1-15 July 2021, MDPI: Basel, Switzerland, doi:10.3390/IECE-10385

Published: 30 June 2021

Publisher's Note: MDPI stays neutral with regard to jurisdictional claims in published maps and institutional affiliations.

Copyright: (C) 2021 by the authors. Submitted for possible open access publication under the terms and conditions of the Creative Commons Attribution (CC BY) license (http://creativecommons.org/licenses /by/4.0/).
Tehran University, Entomology Department, Iran

* Correspondence: keshavarzd25@gmail.com

+ Presented at the 1st International Electronic Conference on Entomology (IECE 2021), 1-15 July 2021; Available online: https://iece.sciforum.net/.

\begin{abstract}
The insect successional wave is a primary method to estimate the time elapsed since death. Several studies have shown that antemortem consumption of opioids affects maggot growth rates. However, there are no published data that investigate the effect of antemortem opioids uses on successional patterns. Therefore, the purpose of this research was to investigate the effect of methadone on the successional patterns of insects on rabbit carcasses.During this successional study, 15 and 12 insect taxa were recorded on carcasses for $15 \mathrm{~d}$ sampling intervals during spring and winter 2018, respectively. Chrysomya albiceps and Calliphora vicina were the most frequent fly species. These two species preferred to lay eggs on the control carcasses earlier than the treated carcasses. Lucilia cuprina was observed exclusively on the remains of untreated carcasses, while Saprinus chalcites was recorded only from the remains of treated rabbits. Permutation analyses based on the Mantel test for the similarity values of taxa between treated and untreated carcasses in the spring and winter were $0.64(\mathrm{P}=0.009)$ and $0.69(\mathrm{P}=0.003)$, respectively. Permutation analyses for the two most dominant fly species between the treated and untreated carcasses in the spring and winter were $0.51(\mathrm{P}$ $=0.05)$ and $0.49(\mathrm{P}=0.09)$, respectively. The results revealed that the overall pattern of insect succession was similar between the treated and untreated rabbit carcasses. However, the patterns of succession of Chrysomya albiceps and Calliphora vicina were slightly different between both treated and untreated carcasses and this could have an influence on the PMI estimation.
\end{abstract}

Keywords: Forensic entomology; insect succession; methadone

\section{Background}

Synthetic opioids deaths continue to rise in different parts of the world [1-3]. More than 42,000 deaths due to opioid overdose have been reported in the United States in 2016 [2]. Methadone is a synthetic opioid drug with a high attraction to $\mu$ receptors that prescribed for the treatment of opioid addiction [4]. Methadone is a widely used drug in Iran and 1274 related deaths were reported from Tehran during 2009-2015 [1].

In numerous opioids -related deaths, the deceased persons are not discovered until they are in late stages of decomposition. In such cases, forensic entomology is a reliable method to estimate the postmortem interval (PMI) [5]. The degree of development and successional patterns of insects are two main techniques for estimating PMI. By the successional method, the PMI of a corpse is estimated by comparing the composition of corpse insect fauna with the composition of baseline fauna [6]. Necrophagous species include dipteran and coleopteran species are the most important orders for PMI determination in different stages of decomposition [7].

The effects of drugs on the development rate/time of maggots that cause errors in PMI estimation have been reported in different studies, for example; heroin, codeine, and 
methamphetamine decreasing larval development time and increasing the larval growth rate [8-10].

The effect of methadone on the development rate/time of maggots has also previously been investigated and found to be responsible for retardation in the developmental time of the Calliphora vicina species [11]. However, there are no published data that investigate the effect of antemortem methadone use on successional patterns.

Hence, the current study described here attempts to determine whether antemortem consumption of methadone affects successional patterns of insects on decaying remains.

\section{Materials and Methods}

\subsection{Study Sites}

The study was conducted in winter (late-January to March) and spring (late-April to May) of 2018 in the Research Station of Kazerun $\left(29^{\circ} 37^{\prime} 10^{\prime \prime} \mathrm{N} 51^{\circ} 39^{\prime} 15^{\prime \prime} \mathrm{E}\right)$, a research facility of Tehran University of Medical Sciences located in Kazerun County in southwest Fars and is

$860 \mathrm{~m}$ above sea level. The climate in the area is temperate with average temperatures in the spring and winter of 28.0 and $10^{\circ} \mathrm{C}$, respectively. Average annual rainfall is 257 $\mathrm{mm}$ and the most precipitation falls in February, with an average of $62 \mathrm{~mm}$.

\subsection{Carcasses and Methadone Dosing}

Four rabbits ( $\approx 1.8-2 \mathrm{~kg}$ ) obtained from the Animal Lab at Shiraz University. Two animals were administered methadone before euthanasia and two were used as controls. To imitate real human methadone consumption, trial rabbits in the first day received 2 $\mathrm{mg} / \mathrm{kg} /$ day methadone orally by gavage and then the dosages were gradually increased to $20 \mathrm{mg} / \mathrm{kg} /$ day over two weeks. At the end of the period, to ensure rabbits are dependent to methadone, naloxone $(0.5 \mathrm{mg} / \mathrm{kg}$ i.m.) was injected and opiate withdrawal signs (i.e. ptosis and teeth chattering) were observed. At the end of the treatment period, the animals were killed by chloroform in the morning and placed in separate wire cages $(75 \times 50 \times 65$ $\mathrm{cm}$ ) with a $2 \mathrm{~cm}$ steel-welded tubing, which was surrounded with $1.3 \mathrm{~cm}$ mesh. The bottoms of the cages were directly in contact with the ground. The cages were placed in an outdoor site of a research station approximately $80 \mathrm{~m}$ apart and allowed to decay. All cages received direct sunlight most of the day. Permission to use rabbits as the research animal for the present study was granted by the Ethical Committee of Tehran University of Medical Science.

\subsection{Sampling Protocol and Statistical Analysis}

Sampling of insects was conducted daily (between 13:00 -16:00 hr) during winter and spring seasons. In the spring, sampling was done twice daily, for fresh and blot stages of decomposition and then once per day for the next stages, in the winter, sampling was done once per day, for 4 days and then twice daily, for the next days. This was done in accordance with Tabor et al study [5]. Samples of adult beetles and maggots were collected, using pitfall traps and forceps. In the present study, immature stages of flies were chosen for the study of succession patterns and during each visit, adult flies activity was recorded. Approximately 20 larvae were collected from each maggot mass during samplings and then they were put in hot water to die. Another group of 20 larvae was collected for rearing to the mature stage. Different taxonomic keys were used for the identification of insect samples [12-15].

Jaccard similarity coefficients were used to determine the match of species between sampling intervals within the experimental carcasses. The Jaccard index ranges from 0-1 demonstrating complete dissimilarity to perfectly match between sampling intervals for any insect species [5]. Average similarities of species between the sampling intervals were calculated for both treated and control groups. Then, similarities were tested using a permutation analysis. In the present study, the H-null hypothesis representing dissimilarity between the successional waves of species from testing and control carcasses $\left(\mathrm{H}_{0}\right.$ : $P=0)$. 
Shannon diversity index $\left(\mathrm{H}^{\prime}=-[\Sigma\right.$ (pi lnpi)], where $\mathrm{pi}=\mathrm{ni} / \mathrm{N}$ [ni is the number of specimens of taxon i]) was obtained to determine species diversity in each season [16]. For the analysis of differences between Shannon's values, the diversity $t$-test was used. The analysis was done with PAST software version 3.14 (Paleontological Statistics Software Package). The accuracy of Jaccard similarity between groups was tested by the Jackknife method $(\mathrm{Pi}=\mathrm{J}+(\mathrm{n}-1)(\mathrm{J}-\mathrm{J})$, where $n$ is the number of sampling intervals, $\mathrm{J}$ is the overall resemblance and $\mathrm{J}_{\mathrm{i}}$ is the partial estimate of $\mathrm{J}$ when it sampling interval is removed [17].

\section{Results}

During this study, 15 and 12 insect taxa were identified in spring and winter, respectively. The total number of insects collected on treated and control carcasses were 621 and 912 individuals, respectively (Figure 1). The results in Tables 1 and 2 represents the successional waves of insect species on carcasses of methadone-treated and untreated rabbit during 15 sampling intervals in the spring and winter, respectively.

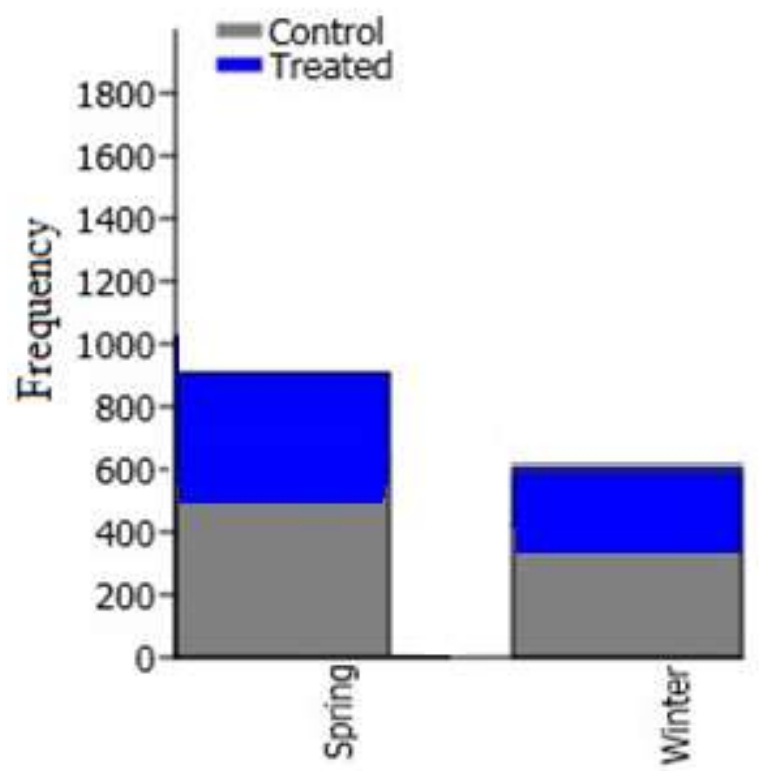

Figure 1. Abundance of insects attracted to the treated and untreated carcasses in spring and winter 2018.

Table 1. Insect succession pattern for Methadone-treated and untreated rabbit carcasses during 15 sampling intervals in spring 2018.

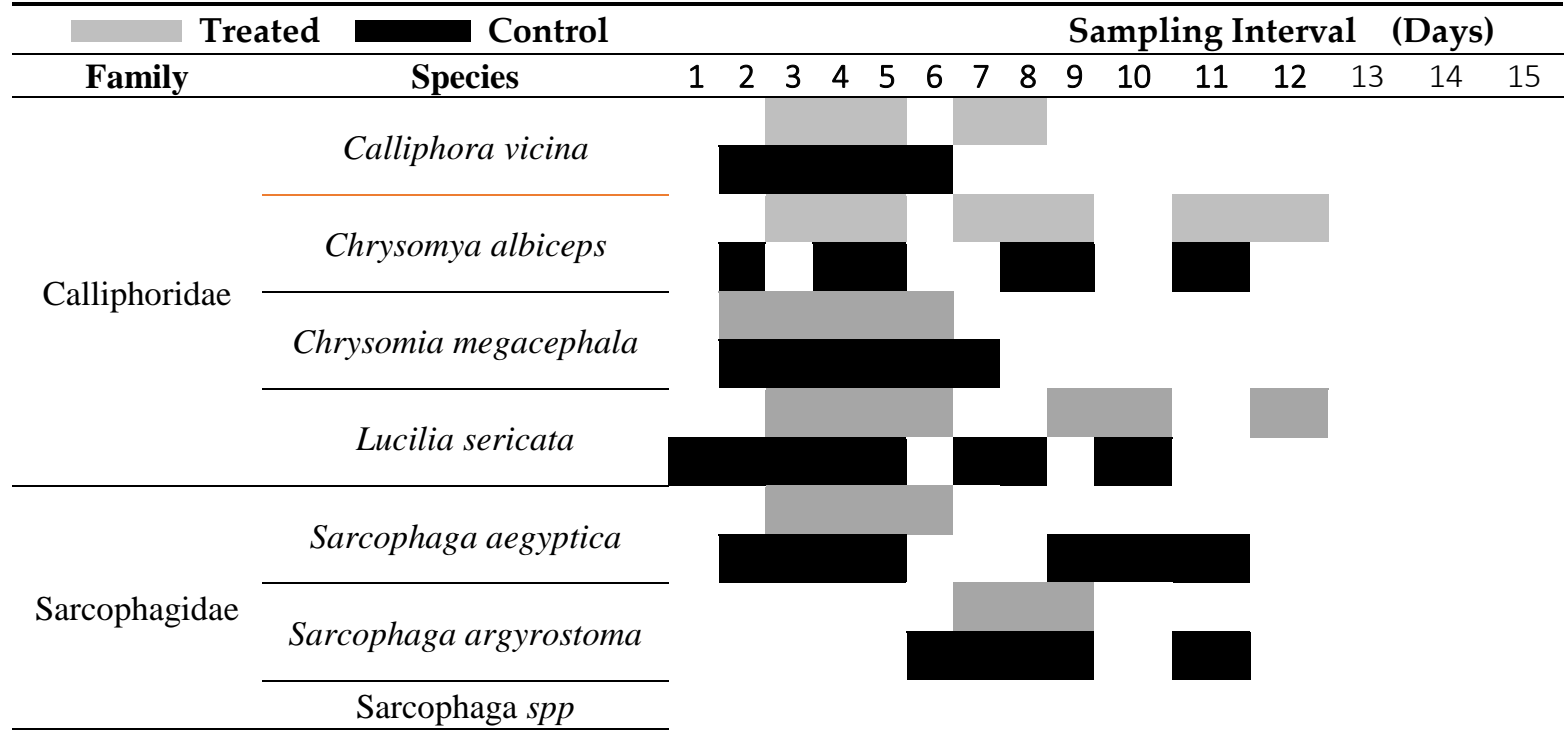




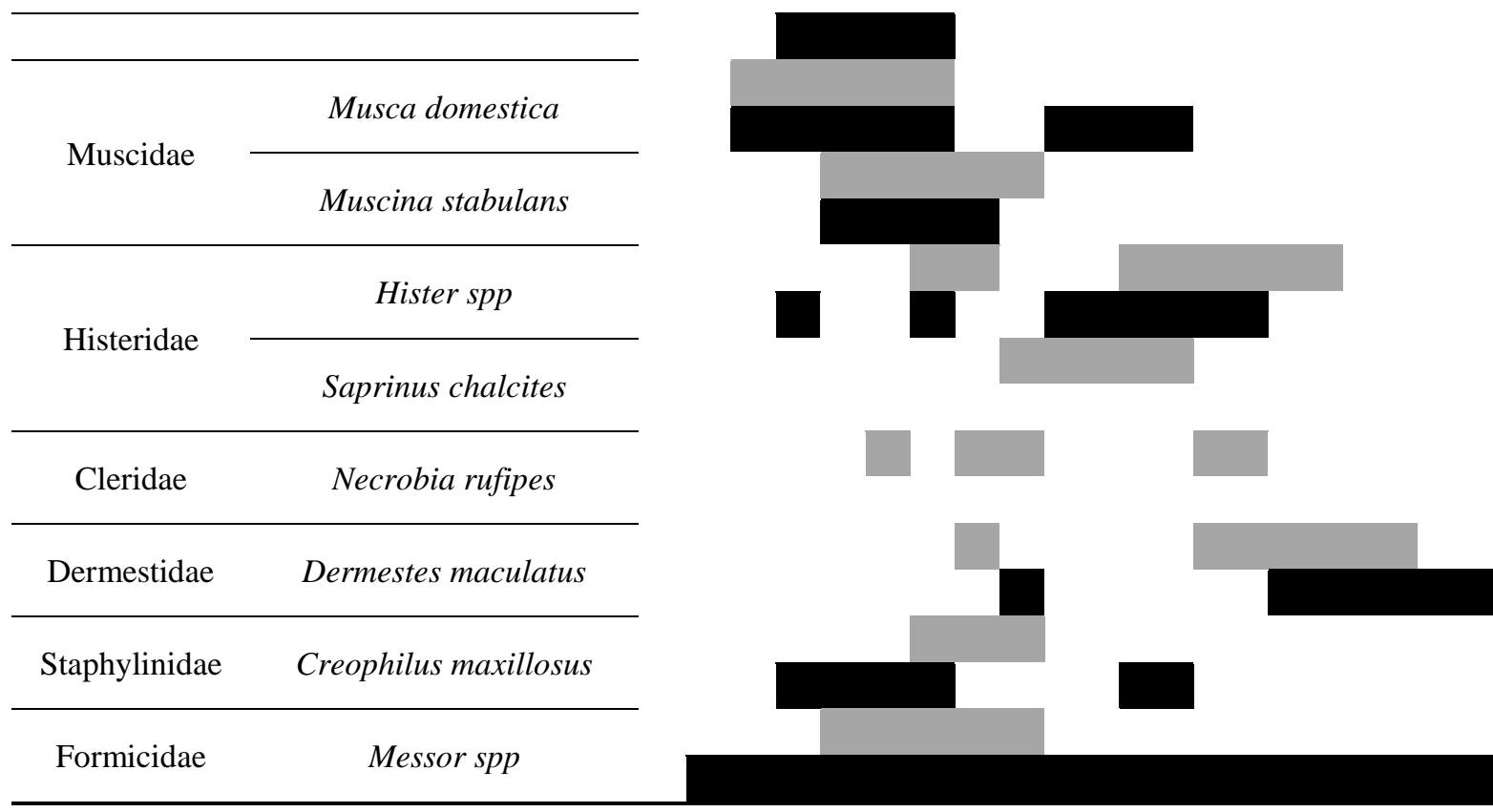

Table 2. Insect succession pattern for Methadone-treated and Untreated rabbit carcasses during 15 sampling intervals in winter 2018.

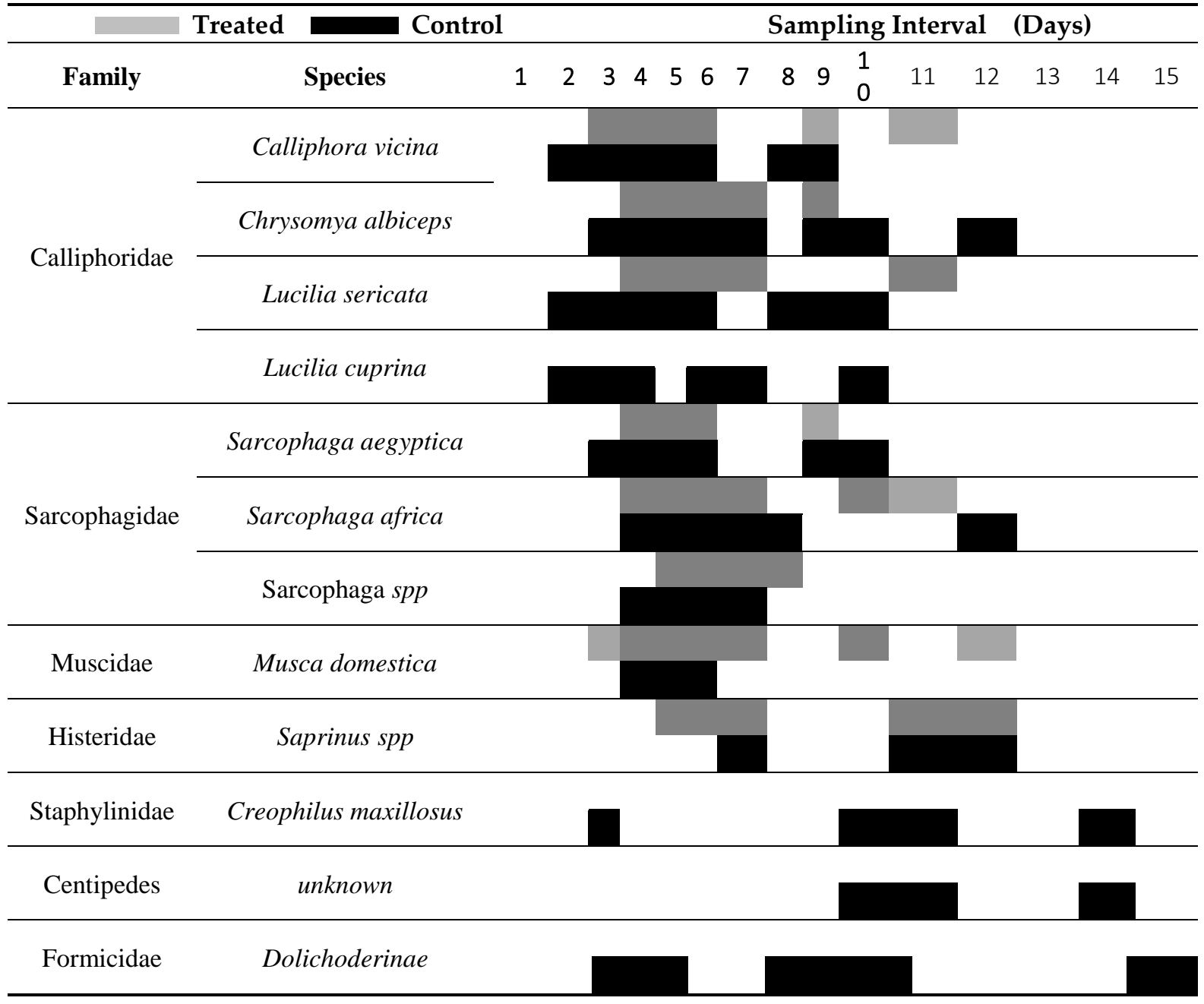

Twelve taxa of dipterans in 3 families were demonstrated in the study. Ten of the dipteran taxa were found on both treated / untreated carcasses; however, two of them (Sarcophaga spp , Lucilia cuprina) were observed only on untreated carcasses. Chrysomya 
albiceps and Calliphora vicina were the dominant fly species in the spring and winter, respectively, and comprising $>35 \%$ of the specimens collected. Dipteran species were the first visitors to carcasses during spring and winter. Chrysomia megacephala was restricted to spring and observed on the remains of both treated and untreated rabbits. The most frequent dipteran larvae were found on untreated carcasses, but the most activity of adult flies was observed in the vicinity of the treated carcasses during fresh and bloat stages. No significant difference was found when comparing the mean number of insect species on treated and untreated carcasses by Mann-Whitney $\mathrm{U}$ test $(\mathrm{U}=86, \mathrm{z}=1.071, \mathrm{P}=0.28)$. Diversity analysis indicates high species richness and species diversity in the spring (Shannon =2.5; Margalef $=2.2$ ). But, the diversity $t$ test analysis on the Shannon index showed no significant difference between spring and winter $2018(\mathrm{P}<0.05)$.

Coleopterans were demonstrated by 6 taxa in 4 families. Four of the beetle species were collected from both treated and untreated carcasses. Creophilus maxillosus was the most dominant beetle species comprising $>60 \%$ of the beetle specimens collected. Saprinus chalcites and Necrobia rufipes were recorded only from the remains of treated rabbits.

Creophilus maxillosus was recorded only from the remains of untreated carcasses during winter.

Formicidae found mostly on the control carcasses with large numbers at early stages of decomposition. Formicidae predated on the eggs and take pieces of carcass parts as food. Messor spp observed on untreated carcasses until the end of the experiment in spring, with their numbers steadily decreasing.

Mean pairwise taxa similarities (Jaccard coefficient) for the successional waves of insect taxa in each sampling period are presented in Figures 2 and 3. The taxa resemblance values for $15 \mathrm{~d}$ sampling intervals during the spring trials ranged from $0.0-0.28$ and 0.05 -0.33 for untreated and treated carcasses, respectively. Those resemblance values during the winter trials ranged from $0.0-0.33$ and $0.0-0.31$ for untreated and treated carcasses, respectively. The lowest resemblances in taxa were observed in the first day of decomposition, but the greatest resemblances were recorded in days 3-5. Correlation analysis was used to test species resemblance values among sampling intervals. Permutation analysis based on the Mantel test between the similarity values of taxa for both treated and untreated groups in the spring and winter were $0.64(\mathrm{P}=0.009)$ and $0.69(\mathrm{P}=0.003)$, respectively. So, correlations were significant at the 0.05 level, therefore, the null hypothesis was rejected. Permutation analysis of the similarities was $0.82(\mathrm{P}<0.001)$ between spring and winter. This result suggest that the successional patterns of insects were similar between spring and winter. 


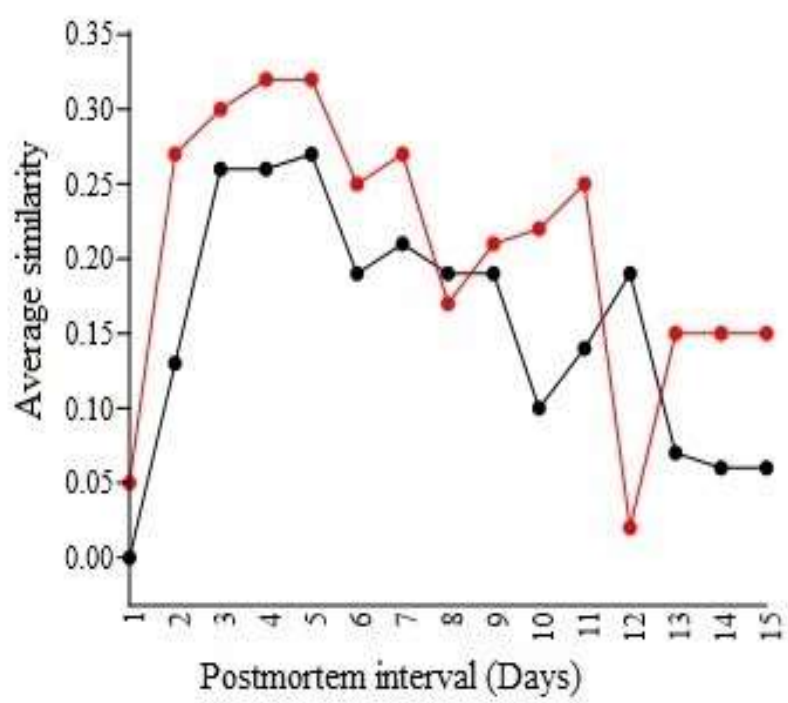

Figure 2. Mean pairwise Jaccard similarities for each sampling interval during the succession of insect species on methadone-treated and untreated carcasses in spring 2018.

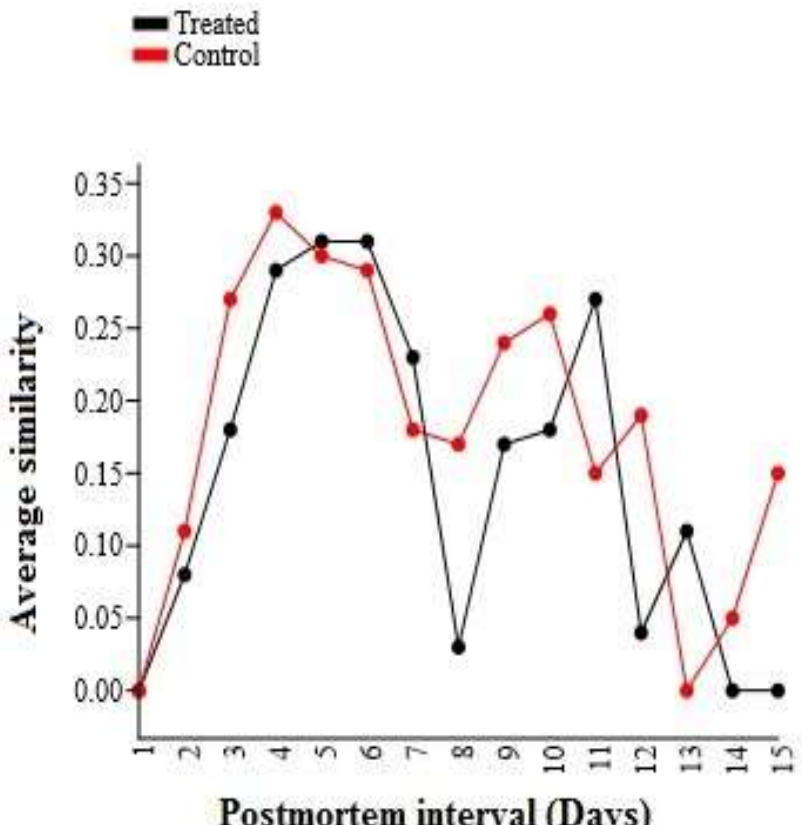

Figure 3. Mean pairwise Jaccard similarities for each sampling interval during the succession of insect species on methadone-treated and untreated carcasses in winter 2018.

Permutation analyses between the similarity values of the two most dominant fly species (Chrysomya albiceps and Calliphora vicina) for both treated and untreated carcasses in spring and winter were $0.51(\mathrm{P}=0.05)$ and $0.49(\mathrm{P}=0.09)$, respectively. Interestingly, this result showed that the successional patterns of those two species on the remains of both treated and untreated rabbits were dissimilar, but colonization of them was similar. Those two species prefers to lay eggs on the control carcasses earlier than the treated carcasses. 


\section{Discussion}

In the present study, decomposition of the control carcasses was faster than the treated carcasses, because of the more number of insects present. This finding is similar to Rodriquez and Bass and Abd El-bar and Sawaby studies [18, 19]. Not amazingly, calliphorid flies were the first visitors to both carcass. This observation was in agreement with previous studies [16, 20]. C. vicina and Ch. albiceps were the dominant species and constituted the primary colonizer in spring and winter, respectively. Abd El-bar and Sawaby reported that $C h$. albiceps is a dominant species and also a primary visitor on carcasses of rabbits treated with an organophosphate insecticide [19]. In this study, we used maggots to study the succession pattern. According to Smith study, the occurrence of adult fly species on the remains doesn't necessarily mean that egg laying or larvi-pvosition is occurring [21]. The most frequent of dipteran larvae were found on untreated carcasses, but the most activity of adult flies was observed in the vicinity of the treated carcasses during the fresh and bloat stages. No significant difference was found after comparing the mean number of larvae between both untreated and treated groups $(P=0.28)$, just contrary to Abd Elbar and Sawaby study for organophosphate treated carcasses [19]. Adult female flies select safe sites for larvi-or oviposition because of the presence of the xenobiotics, predators, and competitors [22, 23]. Mahat indicated that Malathion, in general, delays initial oviposition of dipteran species [23]. Therefore the most activity of adult flies in the vicinity of the treated carcasses may be due to their efforts to choose the right breeding site for larvior oviposition. The taxa resemblance values for $15 \mathrm{~d}$ sampling intervals ranged from $0.0-$ 0.31 and $0.05-0.33$ for untreated and treated carcasses, respectively. These results showed the low similarity in species among sampling intervals within each group, just as Tabor et al. study. for ethanol-treated and untreated pigs [5]. The low similarity degree revealing rapid temporal changes in taxa composition. Therefore, the slowest turnover in taxa composition occurred on days 4-7. The overall pattern of insect succession was similar between the treated and untreated rabbit carcasses $(\mathrm{P}<0.05)$. In parallel, Tabor et al. found that successional patterns of insect species were similar between ethanol-treated and untreated carcasses [5]. Similar findings has been reported in previous studies for organophosphate treated carcasses[19, 24]. In the present study, statistical analysis showed that the succession patterns of the two most dominant fly species (Ch. albiceps and C. vicina) were different between treated and untreated carcasses. This suggested that the antemortem consumption of methadone influenced on the occurrence of those species on the carcasses. According to Tabor et al. study, the C.vicina species preferred to colonize the ethanol - treated carcasses than the control carcasses[5]. Kolver reported that burning had a significant influence on the succession of $\mathrm{Ch}$. albiceps on the carcasses[25]. Differences in the successions of those two species between the carcasses could be due to the effect of methadone on the time of oviposition.

Both Ch. albiceps and C. vicina species, mostly occur during cooler seasons and they are also a first wave invader during the decomposition of carcasses [16, 26].

\section{Conclusions}

We conclude that the overall pattern of insect succession was similar between the treated and untreated rabbit carcasses. But the patterns of the succession of two most dominant fly species (Ch. albiceps and C. vicina) were different between both treated and untreated carcasses. Those two species prefers to lay eggs on the control carcasses earlier than the treated carcasses, and this could have an influence on the PMI estimation based on succession pattern. The current study supplied a database in the field of medico-legal entomology, these data could be useful or estimating minimal postmortem intervals.

\section{References}

1. M. Akhgari, N. Amini-Shirazi, F.S. Iravani, Forensic Toxicology Perspectives of Methadone-associated Deaths in Tehran, Iran, a 7-year Overview, Basic \& clinical pharmacology \& toxicology 122(4) (2018) 436-441.

2. M. Concheiro-Guisan, R. Chesser, J. Pardi, G. Cooper, Postmortem toxicology of new synthetic opioids, Frontiers in pharmacology 9 (2018) 1210. 
3. K. Wolff, Characterization of methadone overdose: clinical considerations and the scientific evidence, Therapeutic drug monitoring 24(4) (2002) 4.57-470

4. A. Hsieh, L. DiGiorgio, M. Fakunle, H. Sadeghi-Nejad, Management Strategies in Opioid Abuse and Sexual Dysfunction: A Review of Opioid-Induced Androgen Deficiency, Sexual medicine reviews 6(4) (2018) 618-623.

5. K.L. Tabor, R.D. Fell, C.C. Brewster, K. Pelzer, G.S. Behonick, Effects of antemortem ingestion of ethanol on insect successional patterns and development of Phormia regina (Diptera: Calliphoridae), Journal of medical entomology 42(3) (2005) 481-489.

6. J. Amendt, C.P. Campobasso, E .Gaudry, C. Reiter, H.N. LeBlanc, M.J. Hall, Best practice in forensic entomology - standards and guidelines, International journal of legal medicine 121(2) (2007) 90-104.

7. E.J.G. Watson, Faunal succession of necrophilous insects associated with high-pofile wildlife carcasses in Louisiana, (2004.(

8. M.L. Goff, W.A. Brown, K. Hewadikaram, A. Omori, Effect of heroin in decomposing tissues on the development rate of Boettcherisca peregrina (Diptera, Sarcophagidae) and implications of this effect on estimation of postmortem intervals using arthropod development patterns, Journal of Forensic Science 36(2) (1991) 537-542.

9. M.L. Goff, M.L. Miller, J.D. Paulson, W.D. Lord, E. Richards, A.I. Omori, Effects of 3, 4-methylenedioxymethamphetamine in decomposing tissues on the development of Parasarcophaga ruficornis (Diptera: Sarcophagidae) and detection of the drug in postmortem blood, liver tissue, larvae, and puparia, Journal of Forensic Science 42(2) (1997) 276-280.

10. H.M. Fathy, R.A. Attia, D.A. Yones ,H. Eldeek, M.E. Tolba, M.S. Shaheen, Effect of Codeine Phosphate on developmental Stages of Forensically Important Calliphoride Fly: Chrysomya albiceps, Mansoura J. Forensic Med. Clin. Toxicol 16 (2008) 41-59.

11. L. Hecht, H. Klotzbach, H. Schröder, K .Püschel, Einfluss von Methadon auf die Entwicklung von Lucilia sericata, Rechtsmedizin 17(2) (2007) 83-88.

12. K. Akbarzadeh, J.F. Wallman, H. Sulakova, K. Szpila, Species identification of Middle Eastern blowflies (Diptera: Calliphoridae) of forensic importance, Parasitology research 114(4) (2015) 1463-1472.

13. Y. Velásquez, C. Magaña, A. Martínez-Sánchez, S. Rojo, Diptera of forensic importance in the Iberian Peninsula: larval identification key, Medical and veterinary entomology 24(3) (2010) 293-30.8

14. A. Grzywacz, M.J. Hall, T. Pape, K. Szpila, Muscidae (Diptera) of forensic importance-an identification key to third instar larvae of the western Palaearctic region and a catalogue of the muscid carrion community, International journal of legal medicine 131(3) (2017) 855-866.

15. B. Bolton, Book Review Identification Guide to the Ant Genera of the World, Psyche: A Journal of Entomology 101(3-4) (1994) 203-208.

16. D. Keshavarzi, M.A. Zaimy, M.A. Yusuf, M. Shahriarinamadi, S. Parkhideh, Insect succession on carrion in Fars Province, southwestern Iran, Egyptian Journal of Forensic Sciences 9(1) (2019) 18.

17. P.M. Dixon, The bootstrap and the jackknife, Design and analysis of ecological experiments (2001) 267-288.

18. W.C. Rodriguez, W.M. Bass ,Insect activity and its relationship to decay rates of human cadavers in East Tennessee, Journal of Forensic Science 28(2) (1983) 423-432.

19 .M.A. El-Bar, R. Sawaby, A preliminary investigation of insect colonization and succession on remains of rabbits treated with an organophosphate insecticide in El-Qalyubiya Governorate of Egypt, Forensic Science International 208(1-3) (2011) e26-e30.

20. A.M.A. Mashaly, F.A. Al-Mekhlafi, Differential Diptera succession patterns on decomposed rabbit carcasses in three different habitats, Journal of medical entomology 53(5) (2016) 1192-1197.

21. R.E.S.o. London, F. Smit, Handbooks for the identification of British insects, The Society1957.

22. M. Archer, M. Elgar, Female breeding-site preferences and larval feeding strategies of carrion-breeding Calliphoridae and Sarcophagidae (Diptera): a quantitative analysis, Australian Journal of Zoology 51(2) (2003) 165-174.

23. N. Mahat, Z. Zafarina, P. Jayaprakash, Influence of rain and malathion on the oviposition and development of blowflies (Diptera: Calliphoridae) infesting rabbit carcasses in Kelantan, Malaysia, Forensic science international 192(1-3) (2009) 19-28.

24. S. Yan-Wei, L. Xiao-Shan, W. Hai-Yang, Z. Run-Jie, Effects of malathion on the insect succession and the development of Chrysomya megacephala (Diptera: Calliphoridae) in the field and implications for estimating postmortem interval, The American journal of forensic medicine and pathology 31(1) (2010) 46-51.

25. J.H. Kolver, Forensic Entomology: The influence of the burning of a body on insect succession and calculation of the postmortem interval, University of the Free State, 2009.

26. T. Sanyanga, Entomological examination of the relationship between ante-mortem and post-mortem amitriptyline concentrations in insects, University of Cape Town, 2016. 